\title{
Training of Foreign Students in the Academic Russian Letter
}

\section{Fedotova Vera Sergeevna ${ }^{1}$}

Associate Professor of A. Pushkin Leningrad State University, St. Petersburg, Russia.

(date of receiving: September, 2017; date of acceptance: January, 2018)

\begin{abstract}
For the foreign student it is very important to own skills of the academic letter. It is an important indicator of professional and research competence of the student. The mobility of foreign graduates of the Russian higher education institutions depends on their level of proficiency in the academic Russian letter as communications between the educational and scientific organizations extend at the international level. Research objective - scientific justification of research tasks for training of foreign students in the academic Russian letter. Research tasks are a modern tutorial of foreign students. The author in article offers-level structure of research tasks of training of foreign students in the academic Russian letter. The author offers three levels of complexity of research tasks. Selection criteria of maintenance of research tasks for training of foreign students in the Russian academic letter - the ideas contextual, activity and personal focused approaches. The author gives a research task, directed to formation of skills of the academic letter in Russian. The author draws a conclusion, that in educational process it is necessary to organize continuity of system research tasks. It helps to create at the foreign student complex ideas of style and features of the academic Russian letter, Skills of the academic letter is a basis for good scientific and professional written and oral communication in Russian.
\end{abstract}

Keywords: Academic Russian Letter, Foreign Student, Russian, Research Tasks, Scientific Text.

1. E-mail:kafivm@lengu.ru 


\title{
Обучение иностранных студентов академическому русскому письму
}

\author{
Федотова Вера Сергеевна ${ }^{1}$
}

Доцент Ленинградского государственного университета имени А.С. Пушкина, Санкт-Петербург, Россия.

(дата получения: сентябрь 2017 г.; дата принятия: январь 2018 г.)

\begin{abstract}
Аннотация
Академическое письмо - важная компонента профессиональной и исследовательской компетентности студента, неотъемлемая черта современного профессионального образования. В условиях расширения связей между образовательными и научными организациями на международном уровне, интеграции и стандартизации мировых образовательных систем успешность и мобильность выпускников российских вузов, в том числе иностранных студентов, во многом определяется их уровнем владения академическим русским письмом. Цель исследования - научное обоснование исследовательских заданий как современного средства обучения иностранных студентов академическому русскому письму. В статье введена уровневая структура исследовательских заданий обучения иностранных студентов академическому русскому письму. Автором выделены три уровня исследовательских заданий по степени сложности. В основу отбора содержания исследовательских заданий для обучения иностранных студентов русскому академическому письму заложены идеи контекстного, деятельностного и личностноориентированного подходов. Приводятся примеры заданий исследовательского характера, направленные на формирование навыков академического письма на русском языке. Сделан вывод, преемственная реализация в учебном процессе системы заданий исследовательского характера позволит сформировать у иностранного студента целостные представления о стиле и особенностях академического русского письма, создаст основу для свободного осуществления профессиональной письменной и устной коммуникации на русском языке и соблюдению норм научной этики.
\end{abstract}

Ключевые слова: Академическое Русское Письмо, Иностранный Студент, Русский Язык, Исследовательские Задания, Научный Текст.

1. E-mail: kafivm@lengu.ru 


\section{Введение}

Долгое время академическое письмо являлось объектом изучения исключительно студентов-филологов, а также научных сотрудников, молодых ученых и диссертантов, которые планировали опубликовать результаты своих исследований в виде научной статьи, реферата, диссертации. Сегодня «академичность» получила широкое распространение. Академическое письмо рассматривается как компонента профессиональной и исследовательской компетентности человека, как элемент научного дискурса, ориентированный на «организацию, оформление и вербализацию знаний академического характера с учетом особенностей научной деятельности и специфики языка» (Колябина 2016. 182). Все более часто стали говорить о формировании академической грамотности личности для обеспечения научной и профессиональной коммуникации, в том числе и международной, о необходимости внедрения в учебную практику отдельной дисциплины «Академическое письмо».Свидетельством усиления внимания общественности к академическому письму также является активное появление новых средств его обучению. Так, например, в последнее время появился блог «Академическое письмо» о том, как написать и опубликовать научную статью (https://writing-skills-development.blogspot.ru), а на портале «Открытое образование» представлендистанционный курс, разработанный СанктПетербургским государственным университетом «Академическое русское письмо». (https://openedu.ru). Сравнительно новое явление в России - открытие центров академического письма при ведущих университетах, миссией которых стало «приобщение магистрантов, аспирантов, молодых научных работников и профессорско-преподавательского состава университета к научному иноязычному дискурсу и формирование у них компетенций для повышения качества научных текстов, предназначенных для публикации в международных журналах, индексируемых аналитическими базами данных, в том числе WebofScience и Scopus» (Базанова 2015. 135). 
Усиление научно-исследовательского компонента в образовательной деятельности вузов, позиционирование академического письма в роли важного компонента речевой деятельности в большинстве профессий объясняютнарастающую тенденцию необходимости всеобщего развития навыков академического письма.

Как следствие сегодня характерно стремительноеувеличение числанаучных публикаций, современных учебников и учебно-методических разработок(Короткина 2015), (Ярская-Смирнова 2013), посвященных разработке методики обучения академическому письму. Однако при всем многообразии информационных ресурсов и возможностей современных образовательных технологий у иностранных студентов, а иногда и у русских студентов - носителей языка до сих пор возникают затруднения в освоении академического русского письма.Это обусловлено тем, что «академическое письмо представляет собой сложный и многоплановый комплекс умений, который сегодня во всем мире признается главнейшим по отношению ко всем другим умениям, которые необходимы для успешного обучения в вузе, непременным условием успешной интеграции в международную научную и профессиональную среду. Этот комплекс умений включает в себя не только лингвистические (языковые, синтаксические и стилистические), но прежде всего металингвистические компетенции, такие как логика, анализ, критическое мышление, объективность и уважение к иным идеям и чужим текстам. Именно этих умений зачастую не хватает нашим студентам и молодым специалистам» (Короткина 2015. 6). По нашему мнению, здесь должен быть сделан акцент на организационно-методической стороне обучения академическому письму. Наиболее трудная ситуация складывается в случае присутствия в русскоязычной аудитории студентов иностранных обучающихся. Иностранный студент,например, получая задание прочитать научный текст (фрагмент монографии/научную статью), идет в библиотеку, 
берет книгу/научный журнал и начинает читать, но при этом чтение у него не получается. Несмотря на то, что студент видит знакомые русские слова, они в комплексе не создают понимания содержания текста.Еще более настораживает тот факт, что иностранный студент не может самостоятельно грамотно написатьсвязный научный текст на русском языке. В результате иностранный студент испытывает ощущение беспомощности и безысходности ситуации. Принимая во внимание тот факт, что иностранные студенты составляют почти треть студентов магистратуры, которые обязаны владеть академическим письмом для написания выпускной квалификационной работы, то возникает тревога за ожидаемые результаты. «Искусство письма как умение, способность излагать мысли, передавать информацию требует многолетней систематической подготовки, разнообразия форм творческой деятельности. Академическое письмо - тем более (Роботова 2011. 48). Таким образом, проблема подготовки иностранного студента к академическому русскому письму в условиях поликультурной образовательной среды вуза требует особого внимания.

По нашему мнению, наиболее целесообразнымсредством обучения иностранных студентов академическому русскому письму является использованиев учебном процессе системы исследовательских заданий, которыепозволят погрузиться обучающимся в научно-профессиональную среду и целенаправленно овладеть не только профильным тезаурусом направления подготовки, но создать естественную среду для овладения навыками создания научного текста на русском языке.

В основу отбора содержания исследовательских заданий для обучения иностранных студентов русскому академическому письму положены идеи контекстного, деятельностного и личностно-ориентированного подходов. В частности, при составлении исследовательских заданий в соответствии с дидактическим принципом доступности отбираются аутентичные тексты, 
которые являются источниками профессиональной информации; содержат важные для рассматриваемой сферы понятия; служат образцами языкового материала, речевых образцов и клише. Обучение академическому письму через чтение аутентичных текстов создает предпосылки для использования читаемого текста в качестве модели для создания в последующем иностранными студентами собственных научных текстов. Формирование навыков использования научного стиля речи реализуется в непосредственно активной деятельности студента, его последовательном переходе от уровня «погружения» к уровню «открытия» в овладении академическом письмом через преемственное формирование умений и навыков письменной научной речи. Кроме того, исследовательские задания, предлагаемые обучающимся, должны быть ориентированы непосредственно на их научные интересы и сферу будущей профессиональной подготовки.

\section{Основная часть}

В условиях расширения связей между образовательными и научными организациями на международном уровне, интеграции и стандартизации мировых образовательных систем успешность и мобильность выпускников российских вузов, в том числе иностранных студентов, во многом определяется их уровнем владения академическим русским письмом.

Целью академического письма является «обучение студентов основам организации и выражения полученных оригинальных знаний в соответствии с научно-исследовательскими критериями соответствующей области знаний, специфики предмета познавательной деятельности, особенностями вербализации знаний в изучаемом языке, формой выбранного жанра академического письма. Магистрант должен быть способен и готов точно и корректно сформулировать задачи и результаты исследования, что предполагает не только создание специальных текстов в основных научных 
жанрах, но также редактирование и грамотное оформление текстов» (Колябина 2016. 182). Академическое письмо характеризуется рядом специфических особенностей: «использованием понятийного языка и терминологического аппарата, линейной логикой развертывания мысли, максимальным устранением разночтений, приведением доказательств каждого утверждения» (Мороз 2015. 38), «объективность, безличностное изложение, насыщенность терминологией, использование речевых стратегий аргументации, четко обозначенные причинно-следственные связи»(Макарова 2014. 13).

Учеными выделены жанры академического письма: первичный (научная статья, рецензия, монография, диссертация и др.) и вторичный (аннотация, тезисы, автореферат, описание научного проекта и др.), структурирующая научное изложение лексика. Отмечается, что в современной системе образования студенты должны владеть каждым из жанров и научной лексикой на определенном уровне. Так бакалавры должны уметь проектировать элементы научного текста (обосновывать актуальность, характеризовать противоречия, описывать проблему, проектировать цели и задачи исследования). В продолжение перечисленных навыков научноисследовательской деятельности магистры должны составлять научный текст (магистерская диссертация, научная статья и т.п.), аннотировать, реферировать, представлять результаты в виде научного проекта, конкурсной научной работы. Не только оформлять, но и понимать научный текст других исследователей. Одной из актуальных проблем обучения иностранных студентов академическому русскому письму является обучение научному стилю речи.

В понимании, что этапы развития научной деятельности включают в себя этап совершения и этап оформления открытия, следует заметить, что научный стиль речи характеризует второй этап - этап речевого оформления открытия. 
Письменное представление научного стиля речи - академическое письмо представляет собой форму существования научного знания, требует соблюдения информационной точности, логичности, целостности, выразительности.

Становление и совершенствование владения академическим языком студентов в России требует разработки эффективных способов и приемов работы с научными текстами. Формирование навыка академического письма является «безусловным трендом в современной образовательной ситуации»(Баребина 2015.30).

В научной литературе авторами предприняты попытки к обоснованию методов и моделей обучения чтению и письму научных текстов, в частности, обозначены следующие направления работы:

1. Изучение структурных блоков научного текста (Макарова 2014).

2. Трансдисциплинарный и внутридисциплинарный подходы к формированию академической речи параллельно освоению профессиональных дисциплин(Короткина 2018).

3. Формирование набора лексических средств связности для организации высказывания, обогащение запаса аутентичных научных оборотов, используемых в научных работах, оборотов научной речи и распространенных устойчивых сочетаний (Дугарцыренова 2016).

4. Обучение академическому письму через чтение (Нужа 2013) и др.

Данный перечень выделенных подходов, по-нашему мнению,можно объединить общей концепцией обучения иностранных студентов академическому русскому письму -использованием системы исследовательских заданий.С учетом выделенных в научной литературе трудностей, с которыми сталкиваются студенты при проектировании научного текста морфологического, лексического, грамматического, стилистического характера нами выделено три уровня исследовательских заданий, 
используемых в обучении академическому письму: уровень «погружения», уровень «приобретения умений и навыков письменной научной речи», уровень «открытия».

Уровень «погружения» - это начальный уровень, который предполагает получение исходныхзнаний о научном стиле речи. Второй уровень ориентирован на приобретение обучающимися умений и навыков письменной научной речи. Третий уровень - уровень открытия - создание научных текстов, письменное описание планируемого научного исследования.

Нами был рассмотренпроцесс и результат внедрения в педагогическую практику исследовательских заданий в системе обучения иностранных студентов в классическом университете. Классический университет представлен в образовательной деятельности многочисленным перечнем образовательных программ различного профиля.Безусловно, приемы и пути обучения академическому русскому письму студентов зависят от индивидуального стиля мышления и опыта научно-исследовательской деятельности обучающихся. Однако в учебных целях этот процесс можно разбить на этапы и реализовать различным содержанием исследовательских заданий, что обеспечит последовательное и преемственное формирование навыков академического русского письма.

В предложенной уровневой структуре обучения академическому письму в основу положена используемая в школьной практике совокупность приемов обучения письму в целом: демонстрация педагогом образцов написания текста, списывание текста с готового образца, освоение правил письма, анализ ошибочного написания.Важными педагогическими факторами при этом является предоставленнаявозможность зрительного восприятие русскоязычного текста, соблюдение принципа наглядности, преемственности, природосообразности. 


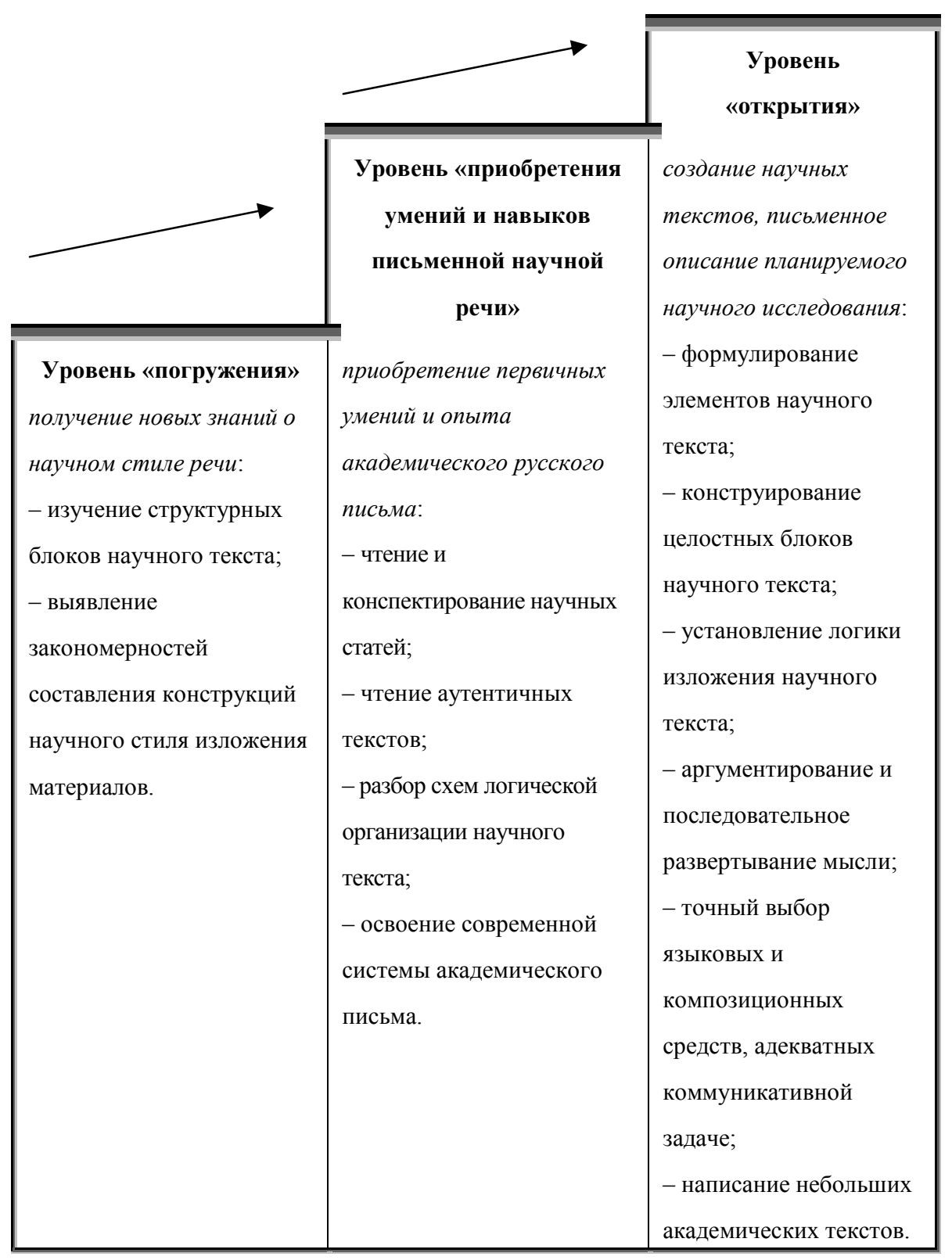

Рис. 1. Схема преемственного формирования навыков академического письма у иностранных студентов. 
Приведем примеры возможных исследовательских заданий различного уровня, ориентированных на подготовку иностранного студента к академическому русскому письму. Система заданий предопределенаобщим заданием - прочитатьуказанный преподавателем фрагмент текста монографии Н.В. Бордовской «Диалектика педагогического исследования» (Бордовская 2016). Далее студенту предлагается выполнить комплекс заданий.

Задание 1 (уровень погружения).Выделитеключевые слова, раскрывающие основную мысль текста,выпишите глаголы, отражающие процедуру работы с информацией, а также отметьте типичные обороты, обеспечивающие логическую связь предложений в тексте. При необходимости обратитесь к толковому словарю.

Ключевые слова - это семантическое ядро статьи, смысловой блок, наиболее полно отражающий тематику и содержание текста. Ключевые слова необязательно должны встречаться в тексте, но должны отражать ответы на вопросы: «чему посвящен текст?», «какие слова наиболее точно отражают объект и предмет исследования?», «какова цель и задачи исследования?». Ключевые слова помогают определить более точно специализацию и круг рассматриваемых вопросов текста, не читая материал полностью.

Примерь глаголов: адресуется, акцентируется, анализируется, аргументируется, демонстрируется, классифицируется, обсуждается, отмечается, рассматривается, характеризуется.

Примеры типичных оборотов: следует отметить.., по мысли автора..., с нашей точки зрения..., приведем пример...

Задание 2 (уровень погружения). Составьте каталог Интернет-ресурсов, посвященных характеристике научного стиля речи.

Задание 3(уровень погружения). Выстройте логику научного аппарата рассматриваемого научного текста.

Задание 4 (уровень приобретения умений и навыков письменной 
научной речи).Выделите основное содержание прочитанного текста и составьте его краткий конспект в виде ментальной карты (визуализировать ключевые идеи текста и показать связи между ними), в виде линейного конспекта (последовательное изложить содержание текста), в виде списка позиций (продемонстрировать различные точки зрения).

При составлении конспекта используйте ответь на стандартные вопросы: В чем заключается главная идея автора? Как автор эту идею доказывает, какие свидетельства привлекает? Согласны ли Вы с этой точкой зрения? Соотносятся ли мысли автора с Вашими аргументами? Каковы ключевые моменты основных частей текста? На какой вопрос стремится ответить автор? Как выразить содержание текста в нескольких фразах?

Задание 5 (уровень приобретения умений и навыков письменной научной речи). Дайте определение приведенным словам и словосочетаниям терминологического характера, которые составляют основу языка науки: актуальность темы, аспект, гипотеза, диссертация, категория, концепция, краткое сообщение, ключевое слово, метод исследования, методология научного познания, наука, научная дисциплина, научная тема, научная теория, научное исследование, научное познание, научный доклад, научный отчет, научный факт, обзор, объект исследования, определение, предмет исследования, понятие, принцип, проблема, теория.

Задание 6 (уровень приобретения умений и навыков письменной научной речи). На примере самостоятельно выбранной научной статьи определите ее композицию, охарактеризуйте логику построения текста, определите методологическое основание, положенное автором в основу статьи.

Задание 7 (уровень приобретения умений и навыков письменной научной речи). Обоснуйте актуальность темы прочитанного фрагмента текста с использованием предложенных лексико-грамматических моделей. 
Примеры лексико-грамматических моделей обоснования актуальности: «в последнее время»/ «в наши дни особую актуальность приобретает изучение проблем ...», «многие исследователи обращаются к теме ...», «на современном этапе проблема ... находится в центре внимания исследователей», «актуальность исследования обусловлена ...», «актуальность работы определяется ...», «... и это определяет актуальность нашей работы», «... поэтому обращение к данной теме является особенно важным», «тем не менее до сих пор не выявлено (не описано, не систематизировано, не установлено...)», «однако...», «несмотря на это...».

Задание 8 (уровень приобретения умений и навыков письменной научной речи). Сформулируйте проблему исследования с использованием предложенных лексико-грамматических моделей.

Примеры лексико-грамматических моделей формулировки: «в работе рассматривается...», «затрагивается вопрос...», «противопоставляются различные точки зрения...», «очерчен круг проблем, связанных с ..», «вскрывается специфика...», «предложен анализ процесса, явления, факта...».

Задание 9 (уровень приобретения умений и навыков письменной научной речи). Изложите цели исследования с использованием предложенных лексико-грамматических моделей.

Примеры лексико-грамматических моделей обоснования актуальности: вводное клише - «в цели исследования входит...», «целью работы является ...»; конкретизация цели - «разработать...», «изучить...», «выявить...», «выяснить ...», «рассмотреть...», «описать...», «обосновать...», «определить...», «создать...», «разработать...», «классифицировать...», «охарактеризовать...», «проанализировать...», «установить...», «доказать...» и др.

Задание 10 (уровень приобретения умений и навыков письменной научной речи). Проанализируйте используемый в исследовании подход с использованием предложенных лексико-грамматических моделей. 
Примеры лексико-грамматических моделей обоснования актуальности: «автор делает обзор...», «затрагивается вопрос...», «автор утверждает...», «автор подвергает критике..., «автор строит свое исследование исходя из...», «предлагает свою концепция...», «исследование основано на идее ...».

Задание 11 (уровень открытия). На примере самостоятельно выбранной научной статьи определите еe композицию, охарактеризуйте логику построения текста, определите методологическое основание, положенное автором в основу статьи.

Задание 12 (уровень открытия). Изложите свои размышления относительно прочитанного текста. Для определения логики повествования используйте вводные слова и словосочетания, союзы и предлоги.

Примеры вводных слов и словосочетаний: таким образом, также, наконец, с одной стороны, как правило, следовательно, подводя итог, итак, во-первых, вовторых, и т.п.

Примеры союзов: однако, тем не менее, тогда как, в то время как.

Примеры предлогов: несмотря на, благодаря, вследствие.

Задание 13 (уровень открытия). Ознакомьтесь с тематикой и проблематикой предложенного научного текста,сформулируйте тему своего исследования в стилистически и тематически близком ключе. Разработайте исходные предположения (гипотезы) о конечном результате исследования и способах его получения. Проведите собственное исследование данной темы, ссылайтесь на авторитетных в научном сообществе авторов, правильно оформляйте цитирование, обоснуйте собственный взгляд на данную проблему.

Задание 14 (уровень открытия). Подберите научную статью по теме магистерской диссертации. Проанализируйте теоретическое обоснование проблемы, рассматриваемой в статье по приведенной схеме: история возникновения проблемы, гипотеза, основные понятия теории, методы исследования, доводы в пользу или против теории. Проанализируйте 
эмпирические методы, используемые автором: организация исследования; данные, на которые опирается суждение, приемы исследования, выводы относительно полученных данных и возможности практического использования. Используйте уже известные Вам лексико-грамматических модели определения теоретического аппарата исследования.

Задание 15 (уровень открытия).Определите ведущие фундаментальные труды по планируемой к разработке теме выпускной квалификационной работы, охарактеризуйте идеи ведущих авторов по проблеме исследования. Сравните различные подходы авторов к изучаемой проблеме. Представьте и обоснуйте свою точку зрения на исследуемую проблему.

В результате выполнения системы исследовательских заданий, направленных на формирование готовности к использованию научного стиля речи в письменном оформлении исследования - академическом письме, происходит подсознательное формирование так называемой шаблонной речевой матрицы, которая может быть использована иностранным студентов для конструирования собственных письменных научных текстов.

Эффективным приемом в формировании навыков письменной научной речи у студентов является подготовка научной статьи, отвечающей требованиям, например, какого-то серьезного периодического издания. Написание статьи может рассматриваться как комплексная последовательность выполнения всех уровней овладения академическим текстом, как отчетный вид самостоятельной работы студента, на основании которого можно сделать вывод о готовности/неготовности студента к академическому русскому письму.

Контент-анализ требований научных изданий к предоставляемым к публикации материалам показал, что научная статья традиционно включает в себя ряд постоянных компонентов: аннотацию, основную часть, выводы, список используемых источников. При этом аннотация содержит цель, 
методологию, методику и методы исследования, основные результаты, выводы, результаты, обсуждение, обоснование научной новизны и практической значимости. К аннотации прилагается перечень ключевых слов.

Основной текст статьи излагается в следующей последовательности: введение, обзор литературы, материалы и методы, результаты исследования и обсуждение, заключение.

Подготовка введения статьи требует от автора в наибольшей степени внимания и сформированных навыков работы с научным текстом: постановки научной проблемы, обоснования ее актуальности, установления связи с наиболее важными задачами, которые необходимо решить, значение для развития определенной отрасли науки или практической деятельности. Постановка научной проблемы определяет цель и задачи исследования. Обзор литературы предполагает анализ автором источников, на основе которых он будет строить свое исследование; характеристику современных взглядов на проблему; выделение нерешенных вопросов, которым будет посвящена статья. В разделе «Материалы и методы» описывается процесс организации эксперимента, используемые методики, приводятся подробные сведения об объекте исследования; указывается последовательность выполнения исследования и обосновывается выбор используемых методов. Результаты исследования и обсуждение представляют собой основной материал статьи в виде систематизированного авторского аналитического и статистического материала. В заключении в сжатом виде повторяются главные мысли основной части работы, включая прогноз развития рассмотренных аспектов проблемы.

Все этапы подготовки научной статьи можно представить как систему исследовательских заданий дифференциорованного уровня и реализовать их на разных этапах профессиональной подготовки, в пределах одной или разных дисциплин, в составе построения отдельных структурных блоков научного текста. 


\section{Заключение}

Как нам представляется, выполнение преемственных заданий исследовательского характера позволит сформировать у иностранного студента систему представлений о стиле и особенностях академического русского письма, создаст основу для свободного осуществления профессиональной письменной и устной коммуникации на русском языке с преподавателем, однокурсниками инаучным сообществом в целом, будет содействовать использованию различных методов изложения материала (индуктивный, дедуктивный, метод аналогии, контраста, ступенчатый, концентрический), активному участию в дискуссии на семинарских занятиях, созданию на русском языке текстов различных научных жанров (эссе, рецензия, аннотация, реферат, научный обзор литературы, научная статья и пр.), составлению библиографических списков в соответствии с требованиями стандартов, грамотному научному цитированию и соблюдению норм научной этики.

Обучение написанию научных текстов - это обязательный компонент вузовского образования. Таким обучением должны заниматься не только филологи или представители гуманитарных наук, а все преподаватели, планирующие самостоятельную работу студентов по своим дисциплинам. Написанию научных текстов различных жанров необходимо учить всех без исключения студентов, так как любой специалист должен понимать научные тексты, уметь извлекать из них актуальный смысл, важный в профессиональной деятельности, быть в курсе достижений соответствующих наук.

\section{Литература}

1- Базанова Е.М. (2015). Лаборатория научной коммуникации: российский onыm // Bысшее образование в России. № 8-9. С. 135-143. 
2- Баребина Н.С., Баребина А.Д. (2015). Проблема формирования навыков аргументации в обучении академическому письму // Baikal Research Journal. № 1. C. 30.

3- Бордовская Н.В. (2016). Диалектика педагогического исследования: монография. - Москва: Изд-во«КНОРУС».

4- Дугарцыренова В.А. (2016). Трудности обучения иноязычному академическому письму // Высшее образование в России. №6. С. 106-112.

5- Колябина Н.С. (2016). Роль академического письма в формировании общепрофессиональных компетенций магистра // Научные ведомости БелГУ. Серия: Гуманитарные науки. №21 (242). С.180-184.

6- Короткина И.Б. (2015).Академическое письмо: прочесс, продукт и практика. Москва: Изд-во«Юрайт».

7- Короткина И.Б. (2018). Модели обучения академическому письму. Зарубежный опыт и отечественная практика: монография. - М.: Издательство Юрайт.

8- Макарова Л.С. (2014). Развитие навыков научной речи у студентовиностранцев, изучающих русский язык на продвинутом уровне // Вестник Адыгейского государственного университета. Серия 3: Педагогика и психология. №4 (146). С. 112-116.

9- Мороз Д. (2015). Академическое письмо: законь жанра // Наука и инновачии. №147. С.38-39.

10- Нужа И.В., Щемелева И.Ю. (2013). Обучение письму через чтение в курсе английского языка для академических иелей // Вестник Северного (Арктического) федерального университета. Серия: Гуманитарные и соииальные науки. №5. С.113-121.

11- Роботова А.С. (2011). Надо ли учить академической работе и академическому письму? // Высшее образование в России. №10. С.47-55.

12- Ярская-Смирнова Е. (2013). Создание академического текста. Москва: ИздвоООО «Вариант»: ЦСПГИ.

\section{Bibliography}

1- Bazanova E.M. (2015). Laboratorija nauchnoj kommunikacii: rossijskij opyt // Vysshee obrazovanie v Rossii. № 8-9. S. 135-143.

2- Barebina N.S., Barebina A.D. (2015). Problema formirovanija navykov argumentacii v obuchenii akademicheskomu pis'mu // Baikal Research Journal. № 1. S. 30 .

3- Bordovskaja N.V. (2016). Dialektika pedagogicheskogo issledovanija: monografija. - Moskva: Izd-vo «KNORUS». 
4- Dugarcyrenova V.A. (2016). Trudnosti obuchenija inojazychnomu akademicheskomu pis'mu // Vysshee obrazovanie v Rossii. №6. S. 106-112.

5- Koljabina N.S. (2016). Rol' akademicheskogo pis'ma v formirovanii obshheprofessional'nyh kompetencij magistra // Nauchnye vedomosti BelGU. Serija: Gumanitarnye nauki. №21 (242). S.180-184.

6- Korotkina I.B. (2015). Akademicheskoe pis'mo: process, produkt i praktika. Moskva: Izd-vo «Jurajt».

7- Korotkina I.B. (2018). Modeli obuchenija akademicheskomu pis'mu. Zarubezhnyj opyt i otechestvennaja praktika: monografija. - M.: Izdatel'stvo Jurajt.

8- Makarova L.S. (2014). Razvitie navykov nauchnoj rechi u studentov-inostrancev, izuchajushhih russkij jazyk na prodvinutom urovne // Vestnik Adygejskogo gosudarstvennogo universiteta. Serija 3: Pedagogika i psihologija. №4 (146). S. 112-116.

9- Moroz D. (2015). Akademicheskoe pis'mo: zakony zhanra // Nauka i innovacii. №147. S.38-39.

10- Nuzha I.V., Shhemeleva I.Ju. (2013). Obuchenie pis'mu cherez chtenie v kurse anglijskogo jazyka dlja akademicheskih celej // Vestnik Severnogo (Arkticheskogo) federal'nogo universiteta. Serija: Gumanitarnye i social'nye nauki. №5. S.113-121.

11- Robotova A. S. (2011). Nado li uchit' akademicheskoj rabote i akademicheskomu pis'mu? // Vysshee obrazovanie v Rossii. №10. S.47-55.

12- Jarskaja-Smirnova E. (2013). Sozdanie akademicheskogo teksta. Moskva: Izd-vo OOO «Variant»: CSPGI.

\section{HOW TO CITE THIS ARTICLE}

Fedotova Vera Sergeevna (2018). Training of Foreign Students in the Academic Russian Letter, Issledovatel'skiy Zhurnal Russkogo Yazyka i Literatury, 11(1): pp: 159-177

DOI: $10.29252 /$ iarll.11.159

URL: http://journaliarll.ir/article-1-133-en.html

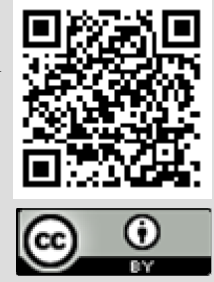


آموزش نمارش آكادميك روسى به دانشجويان خارجى

\author{
ورا سر كئى ويونا فيدوتوا'

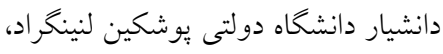 \\ سنيتربورگ، روسيه.

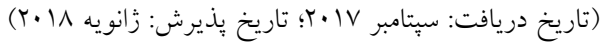

نخارش آكادميك بخش بسيار مهمى از صلاحيتهاى علمى و تخصصى دانشجو را تشكيل

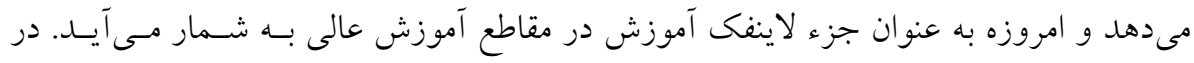

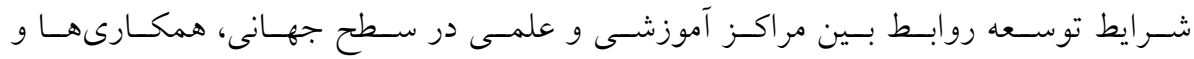

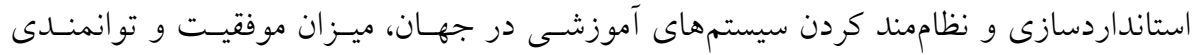

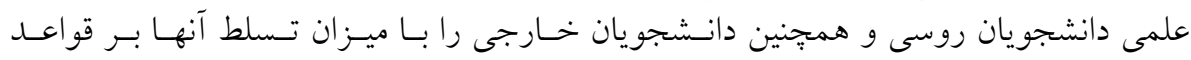

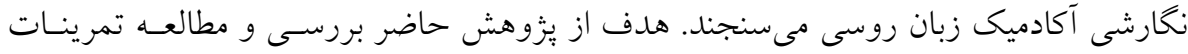

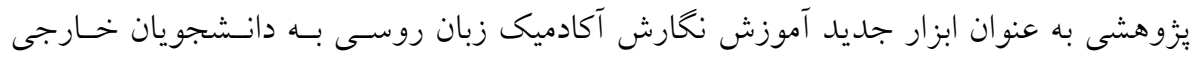

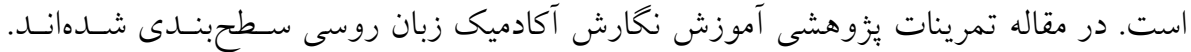

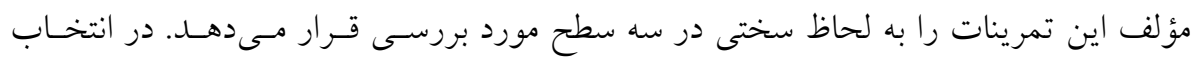

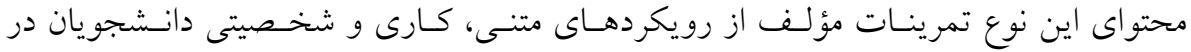

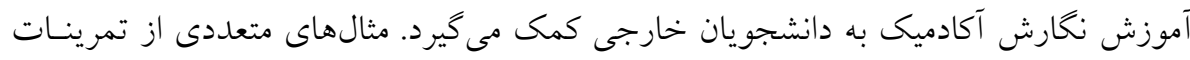

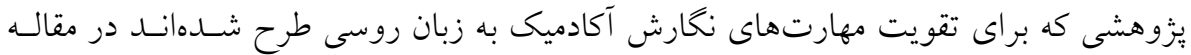

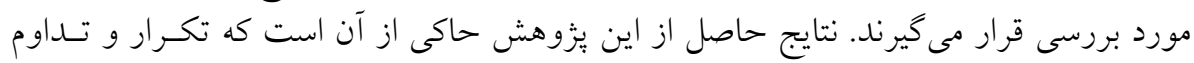

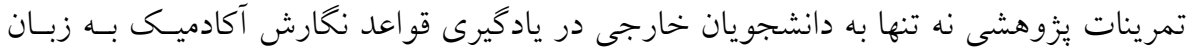

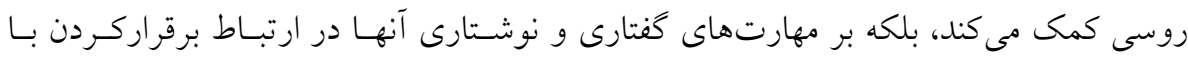

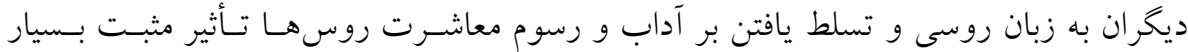
زيادى مى كذارد.

وازگكان كليدى: نخارش اكادميك روسى، دانشجوى خارجى، زبان روسى، تمرينات يزوهـشى،

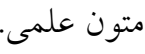

